\title{
Smithsonian Highlights Elections with Exhibit
}

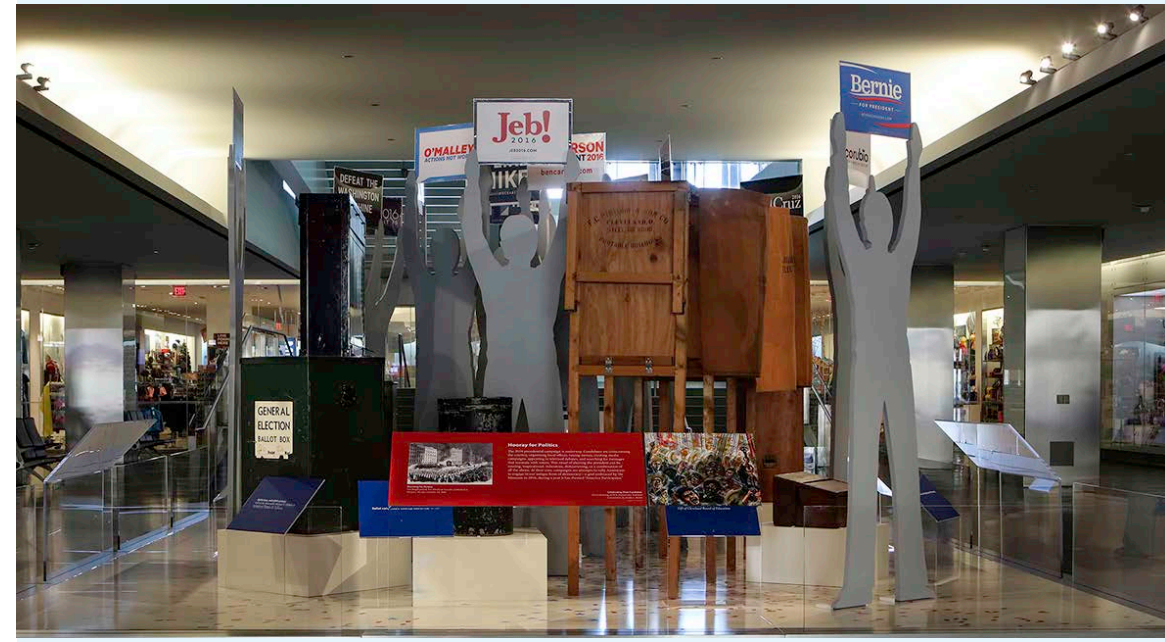

Election signs for candidates still in the race are displayed at the museum's Constitution Avenue, surrounded by historic voting machines and ballot boxes. (All photos courtesy of the National Museum of American History, Smithsonian Institution)

\section{HOORAY FOR POLITICS! EXHIBIT}

To mark the 2016 presidential election year, the Smithsonian's National Museum of American History opened the exhibition "Hooray for Politics!" on February 1. At the museum's Constitution Avenue entrance, mannequins, surrounded by historic voting machines and ballot boxes, hold aloft rally signs from the 2016 presidential campaign.

The signs were provided by the campaigns of declared presidential candidates in the running as of January 25 with the support of more than $1 \%$ in a recognized national poll. During the course of the election, raised signs in the display will indicate contenders still in the 2016 race. As candidates suspend or end their campaigns, their signs will be lowered. Other objects in "Hooray for Politics!" include an automated voting machine invented in 1898, a glass ballot box from the 19th century, and a bank of three wooden voting booths from the 1940 .

In 2016, the museum is organizing its exhibitions, programs, and outreach around the theme "America Participates" to set the stage for a 2017 opening for four programmatic spaces based on the ideal of the nation Americans build together. "American Democracy: A Great Leap of Faith" will be a cornerstone exhibit centered on the country's founding principles, including political participation and engagement. The future show will include an array of campaign materials from the 19th century to the present.

"It is through participation that Americans contribute to our democracy in a multitude of avenues, including voting" said John Gray, the museum's director. "This year we aim to highlight the many ways Americans effect change and we hope to inspire a new generation to participate."

\section{COLLECTING MEMORABILIA}

Continuing a long-standing tradition, curators from the museum's division of political history collected campaign materials and memorabilia from the Iowa Caucuses and the New Hampshire Primary. Lisa-Kathleen Graddy, deputy chair of the museum's Division of Political History, and Jon Grinspan, an associate curator of political history and Jefferson Fellow, collected on behalf of the museum. The curators sought the material culture that represents political engagement, including posters, badges, buttons, ribbons and advertising novelties, as well as materials used by the media and other individuals associated with the political process. In addition to Iowa and New Hampshire, both will attend the July Republican and Democratic National Conventions in July.

\section{SMITHSONIAN'S COLLECTION}

Today, the museum's political history collection includes objects related to presidential history and political campaigning, as well as the history of the White House and first ladies; civil rights, women's suffrage and reform movements; the World War II home front; and labor history. The political history collection includes some of the country's most important national treasures, including the small portable desk on which Thomas Jefferson wrote the Declaration of Independence, the top hat President
Abraham Lincoln wore the night he was assassinated, small metal buttons made to celebrate George Washington's inauguration in 1789 and items from recent presidential elections.

Through incomparable collections, rigorous research, and dynamic public outreach, the National Museum of American History explores the infinite richness and complexity of American history. It helps people understand the past in order to make sense of the present and shape a more humane future. The museum is continuing to renovate its west exhibition wing, developing galleries on democracy, immigration and migration, and culture.

\section{VISITING THE MUSEUM}

For more information, visit http://americanhistory.si.edu. The museum is located on Constitution Avenue, between 12th and 14th streets NW, and is open daily from 10 am to 5:30 pm (closed December 25). Admission is free. For Smithsonian information, the public may call (202) 633-1000.

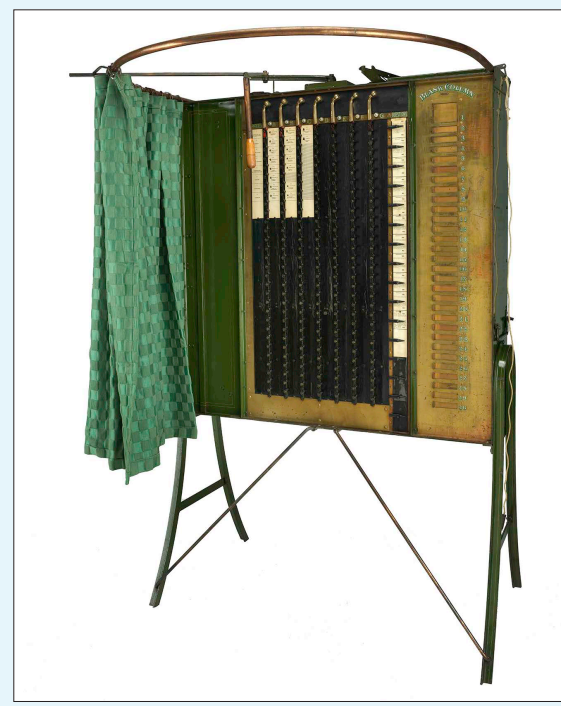

The exhibit includes election-related pieces of history like this automatic voting machine with privacy curtain, invented in lowa, 1898.

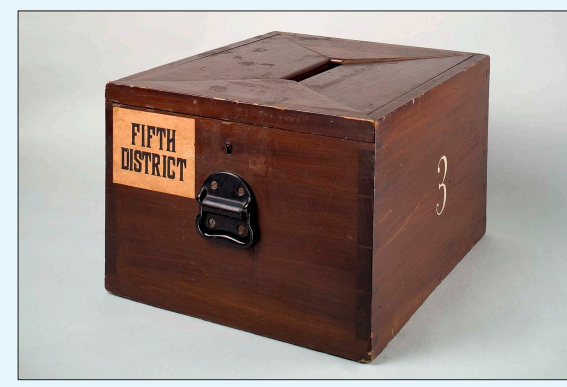

This ballot box, on display, was used in the northeast United States during the 1850s. 